\title{
Changes of microstructure and diffusivity in blended cement pastes exposed to natural carbonation
}

\author{
Wioletta Soja ${ }^{1, \star}$, Hamed Maraghechi ${ }^{1}$, Fabien Georget $^{1}$, and Karen Scrivener $^{1}$ \\ ${ }^{1}$ Laboratory of Construction Materials, EPFL, Lausanne, Switzerland
}

\begin{abstract}
This study compares the phase assemblage and pore structure variation of Portland cement and blended cements, containing limestone and burnt oil shale, during carbonation. Hardened cement paste was exposed to natural carbonation ( $400 \mathrm{ppm}$ of $\mathrm{CO}_{2}$ ) at a relative humidity of $70 \%$ for one year. Samples were prepared and cured at $95 \% \mathrm{RH}$ for 28 days. Reference mixes were exposed to $\mathrm{CO}_{2}$-free atmosphere to decouple the effect of ongoing hydration and drying from that of carbonation. The phase assemblage was investigated using XRD-Rietveld refinement and thermogravimetric analyses. The porosity and pore structure was assessed based on the results from mercury intrusion porosimetry. Additionally preliminary results of gas diffusion experiment of carbonated and non-carbonated samples are presented.
\end{abstract}

\section{Introduction}

Concrete structures are continuously exposed to a certain amount of $\mathrm{CO}_{2}$ in atmosphere (approximately $400 \mathrm{ppm}$ in air), which can penetrate into concrete through the pores, dissolve in pore solution, and react with hydrated phases to form carbonates. The process causes the lowering of the $\mathrm{pH}$ of the pore solution $[1,2]$. This leads to the dissolution of the protective surface oxide layer of the steel reinforcements and their depassivation, leading to corrosion causing deterioration in reinforced concrete structures [3, 4]. The depth of carbonation in concrete is governed by two main phenomena: binding of the $\mathrm{CO}_{2}$ by portlandite and other hydrates and transport of $\mathrm{CO}_{2}$ through the carbonated layer. However, the microstructure of a carbonated layer is different from a non-carbonated layer in concrete. Changes in the pore structure affect the transport of $\mathrm{CO}_{2}$ and thus the rate of carbonation. This study focuses on characterizing changes of the solid phase assemblage due to carbonation. The modified microstructure is going to be linked it with transport properties. Capturing the feedback of the transport properties is necessary to obtain quantitative predictions [5] which will be implemented in a new model coupling carbonation and drying [6]. Correct prediction of carbonation rate will help to estimate a service life of reinforced concrete structures. That is especially important for new cements with supplementary cementitious materials (SCMs) which are more and more in use for concrete structures.

The formation of different calcium carbonate polymorphs in the blends during accelerated carbonation, where $\mathrm{CO}_{2}$ concentration is increased, may not be a good representative of the reality in natural carbonation conditions. The main difference is the formation of more arag-

\footnotetext{
^e-mail: wioletta.soja@epfl.ch
}

onite in accelerated conditions [7]. Aragonite is a calcium carbonate polymorph with a lower molar volume compared to calcite and vaterite. Its precipitation causes a higher porosity in natural carbonation conditions and an easier $\mathrm{CO}_{2}$ ingress. Therefore, in this study the main focus is on natural carbonation. The use of thin paste samples allows to monitor the progress of carbonation over time and to accelerate the rate of carbonation to obtain fully carbonated system in relatively short time.

\section{Materials and Methods}

In this study, three types of cements including CEM I and blended cements, CEM II/B-M (with $13 \%$ of limestone and $14 \%$ of burnt oil shale) and CEM II/B-LL (with 29 $\%$ of limestone) were employed. Their chemical compositions are reported in Table 1.

Table 1. XRF composition of the cements.

\begin{tabular}{llll}
\hline Material & CEM I & CEM II/B-M & CEM II/B-LL \\
\hline $\mathrm{CaO}$ & 62.8 & 59.5 & 64.7 \\
$\mathrm{SiO}_{2}$ & 20.2 & 21.3 & 11.9 \\
$\mathrm{Al}_{2} \mathrm{O}_{3}$ & 4.7 & 5.5 & 3.2 \\
$\mathrm{Fe}_{2} \mathrm{O}_{3}$ & 3.1 & 3.5 & 2.2 \\
$\mathrm{MgO}$ & 2.1 & 1.8 & 1.6 \\
$\mathrm{P}_{2} \mathrm{O}_{5}$ & 0.2 & 0.2 & 0.3 \\
$\mathrm{~K}_{2} \mathrm{O}$ & 1.0 & 1.1 & 0.7 \\
$\mathrm{Na}_{2} \mathrm{O}$ & 0.2 & 0.2 & 0.2 \\
$\mathrm{SO}_{3}$ & 3.5 & 3.2 & 2.7 \\
\hline
\end{tabular}

Paste mixtures were prepared at $w / b=0.4$ using a vacuum mixer and cast in plastic cylindrical molds of diameter $32 \mathrm{~mm}$ and height $70 \mathrm{~mm}$. After one day of sealed curing, the pastes were demolded and exposed to $95 \%$ 
relative humidity. Curing was continued up to 28 days. Cylinders were cut with a slow speed saw to obtain thin slices with a thickness of $1 \mathrm{~mm}$. The slices were exposed to natural carbonation environment at $400 \mathrm{ppm}$ of $\mathrm{CO}_{2}$ and $70 \% \mathrm{RH}$. Moreover, reference mixes were exposed to $\mathrm{CO}_{2}$-free atmosphere with $70 \% \mathrm{RH}$ to decouple the effect of ongoing hydration and drying from that of carbonation.

The phase assemblage of the paste samples was investigated using XRD-Rietveld refinement method and thermogravimetric analysis (TGA). For XRD, the thin disk samples were removed from the chambers at exposure time of 12 months and ground into powder using a mortar and pestle prior to the analysis. Attempts were made to do the grinding as fast as possible to avoid carbonation in samples that were exposed to $0-\mathrm{CO}_{2}$ chamber. The mineralogical evolution induced by carbonation were carried out using PANalytical X'Pert Pro MPD diffractometer in Bragg-Brentano geometry. Scanning was carried out from $5^{\circ}$ to $70^{\circ} 2 \theta$ angles. Crystalline phases were quantified by Rietveld refinement using X'Pert High Score Plus software with rutile as an external standard [8].

For thermogravimetric analysis samples dried by solvent exchange method, using isopropanol for 7 days, followed by drying under vacuum in desiccator for another 7 days. Then samples were ground as for XRD however only $50 \mathrm{mg}$ was used for each test [9]. TGA was carried using a Mettler Toledo TGA/SDTA851 e. The temperature ranged from 30 to $1000^{\circ} \mathrm{C}$. The mass loss as a function of the temperature was obtained. After derivation the DTG curve was acquired that shows various peaks corresponding to the mass loss due to $\mathrm{H}_{2} \mathrm{O}$ release (dehydration, dihydroxylation) until $550{ }^{\circ} \mathrm{C}$ and above $550{ }^{\circ} \mathrm{C}$ due to $\mathrm{CO}_{2}$ release (decarbonation).

The pore structure characteristics of the paste samples was assessed using mercury intrusion porosimetry (MIP) [10] after 12 months of exposure. Samples were dried by solvent exchange method, as for TGA. Then half of the disk from each exposure conditions was broken into several pieces with the total mass of around $0.7 \mathrm{~g}$. Pascal 140 and 440 porosimeters by POROTEC were used for mercury intrusion porosimetry.

For gas diffusion measurement, samples were glued into a metal ring to avoid pressing on the samples during sealing. That prepared sample was placed into a chamber with oxygen detector. The diffusion set-up was based on the design described in [11]. One side of the sample was exposed into the air and other side was purged with nitrogen. The evolution of the oxygen concentration in the top (nitrogen) chamber was used to back-calculate the diffusion coefficient.

\section{Results and Discussion}

\subsection{Phase assemblage studied by XRD-Rietveld and TGA}

Figure 1 presents the evolution of the content of portlandite $(\mathrm{CH})$ and calcite for different systems during drying, and drying together with carbonation, over time. It
Table 2. Total amount of calcium carbonate from XRD (summary of crystalline phases of calcite, veterite and aragonite), TGA (calculated based on the mass loss between $540^{\circ} \mathrm{C}$ and $850^{\circ} \mathrm{C}$ ) and amorphous (TGA-XRD) after 12 months of carbonation.

\begin{tabular}{lccc}
\hline & XRD & TGA & Amorphous \\
\cline { 2 - 4 } & \multicolumn{2}{c}{$\mathrm{g} / 100 \mathrm{~g}$ of } & anhydrous \\
\hline CEM I & 21.3 & 24.0 & 2.7 \\
CEM II/B-M & 61.3 & 69.8 & 8.5 \\
CEM II/B-LL & 82.4 & 88.6 & 6.1 \\
\hline
\end{tabular}

can be seen that the $\mathrm{CH}$ content does not change significantly in system without $\mathrm{CO}_{2}$ which means that hydration is considerably slowed down, and may be negligible. The presence of calcite in noncarbonated CEM II/B-M and CEM II/B-LL systems corresponds to the unreacted limestone present in the initial mixes. For these two blended cements portlandite is consumed more rapidly and more calcite is formed. Other polymorphs of calcium carbonate as aragonite and vaterite were detected only in minor quantities. From the obtained results it can be concluded that the blends are less resistant to carbonation than Portland cement.

Figure 2 shows the TGA and derivative thermogravimetric (DTG) graphs for non-carbonated and carbonating samples. Calcium carbonate peak for blended cements in non-carbonated systems corresponds to the presence of limestone in the original mixes, also shown by XRD. TGA curves of the samples from before exposure does not significantly vary from those during exposure to $70 \% \mathrm{RH}$ without $\mathrm{CO}_{2}$. Therefore only systems before exposure (after 28 days of curing) are presented here. After 12 months of carbonation portlandite is present only in CEM I, while for the blends, it is almost completely depleted. Total amount of calcium carbonate obtained from TGA is higher than from XRD, because XRD can detect only crystalline phases while TGA detect total amount of calcium carbonate including amorphous. Quantification data are summarized in Table 2.

\subsection{Porosity studied by MIP}

Figure 3 shows the pore size distribution in the noncarbonated and carbonated paste samples for CEM I and blended cements. Between $t_{0}$ (before exposure) and $t_{0}+12$ months at no $\mathrm{CO}_{2}$ (at $70 \%$ of $\mathrm{RH}$ ) the pore structure becomes coarser and the critical pore entry size shifts towards higher values. It can be seen that the total porosity does not change significantly during $\mathrm{CO}_{2}$-fee exposure. Porosity redistribution due to drying without noticeable changes in the total porosity was also reported in the literature [12-15]. The MIP results after carbonation in 70 $\%$ RH show a decrease of the total porosity in comparison to the samples from $\mathrm{CO}_{2}$-fee atmosphere. Refinement of the porosity was also observed for all three systems including blended cements. If as reference sample the one from before exposure would be taken then coarsening would be reported for blended cements after carbonation. 

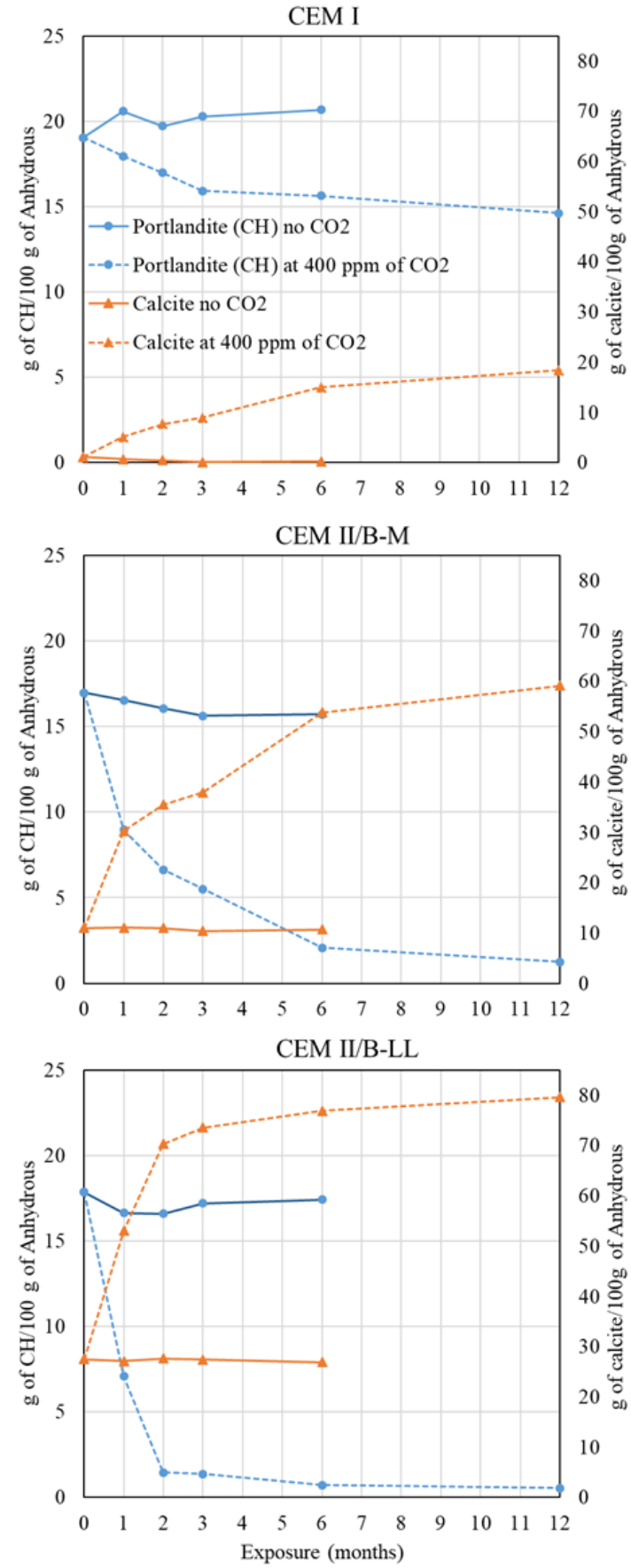

Figure 1. Content of portlandite $(\mathrm{CH})$ and calcite as a function of cement type, exposure conditions and time of exposure.

\subsection{Gas diffusion}

Gas diffusion experiment was performed on the samples made with CEM II/B-LL. These samples show no more significant changes in phase assemblage after 12 months of natural carbonation and almost total depletion of portlandite was observed already after 6 months of carbonation. Preliminary results show that non carbonated discs have higher diffusion coefficient than carbonated ones. It corresponds well with the porosity data obtained from MIP (see Fig. 3). Table 3 presents values of total porosity and

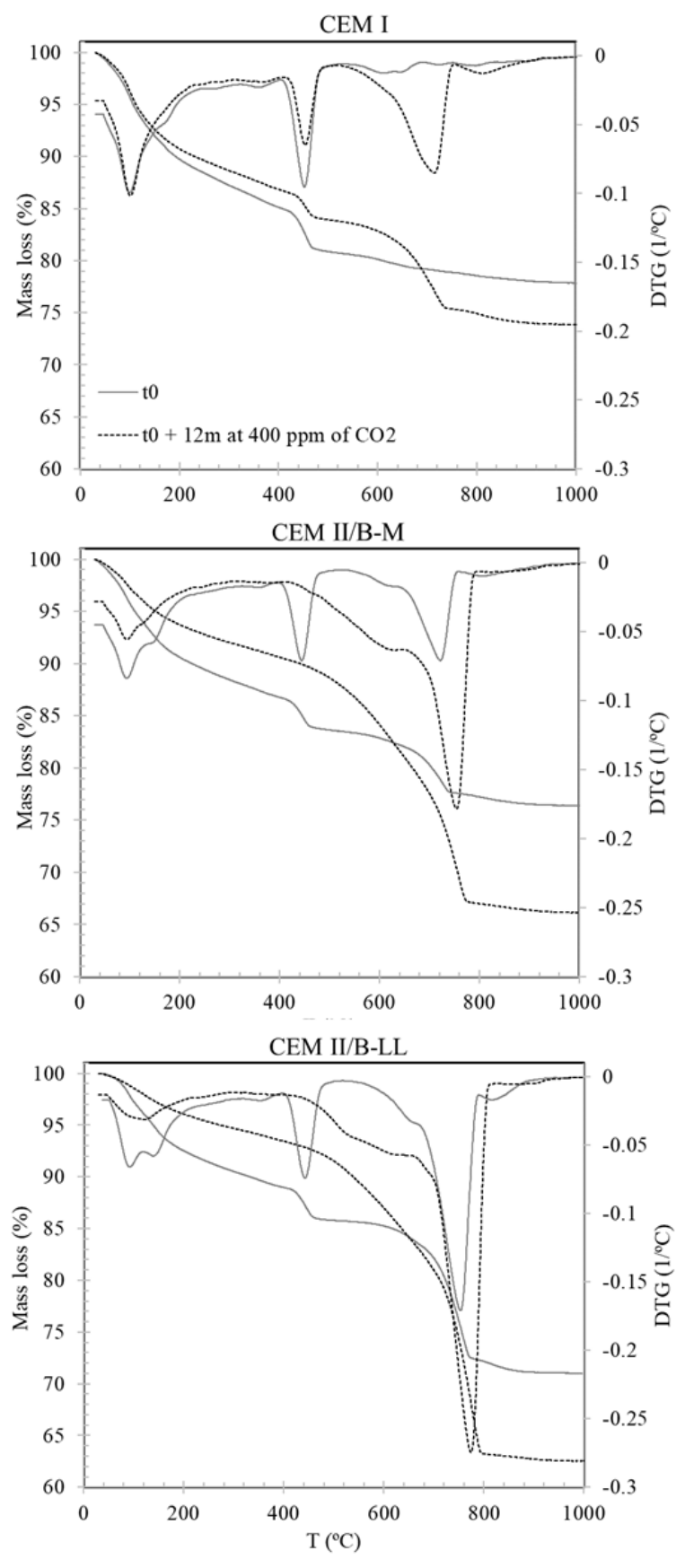

Figure 2. TGA and DTG of the non-carbobated samples (solid line ) and after 12 months of carbonation (dash line).

diffusion coefficient for studied system with one duplicate for each exposure conditions. The duplicates prove good repeatability of the experiment. The diffusion experiment for the other systems will be performed after longer carbonation, when full carbonation will be reported without further changes of calcium carbonate content. The results will help to obtain correct diffusion coefficient of the carbonated materials which will be implemented into a new carbonation model [6]. 

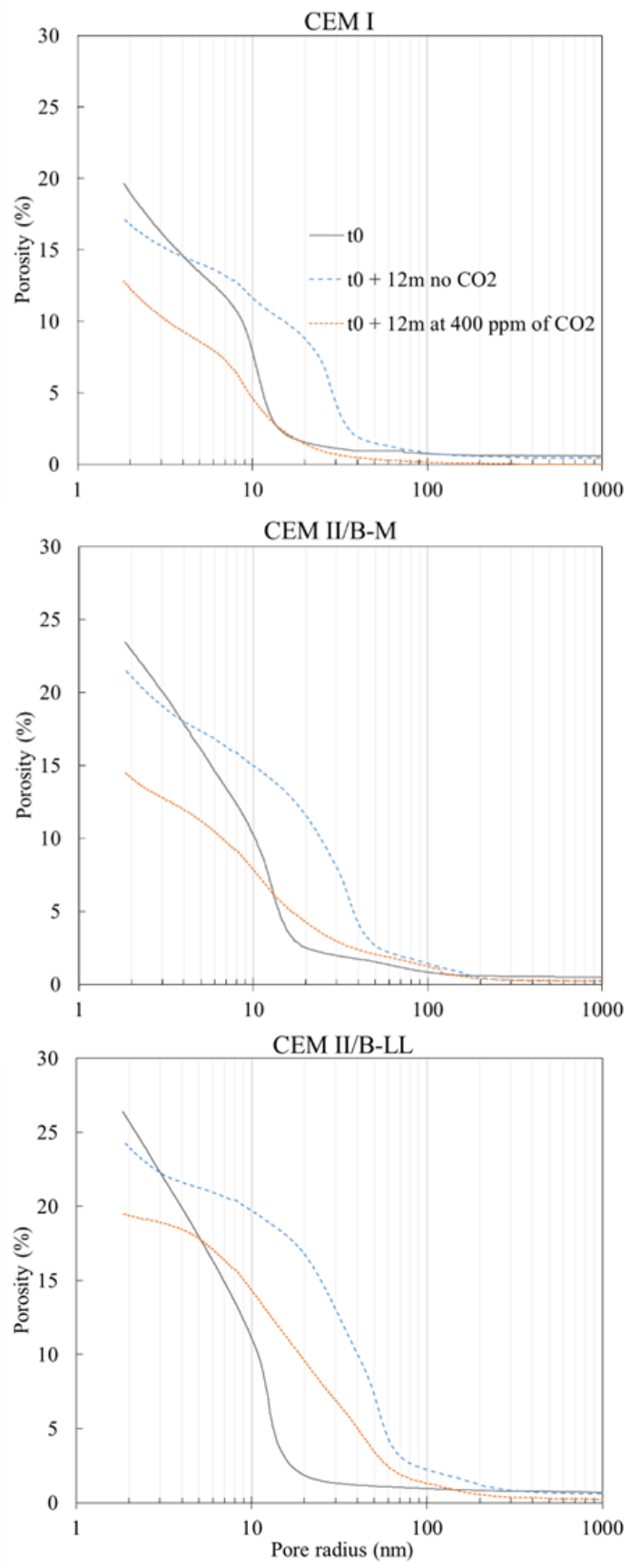

Figure 3. Porosity analysis of $\mathrm{PC}$ and blended cements exposed to $70 \% \mathrm{RH}$ and 400 or $0 \mathrm{ppm}$ of $\mathrm{CO}_{2}$; exposure for 12 months after 28 day $\left(\mathrm{t}_{0}\right)$ of curing.

\section{Conclusions}

This study focused on the investigation of the microstructural and mineralogical changes that happen due to natural carbonation in Portland cement and blended cements including limestone and burnt oil shale. Higher portlandite consumption for blended cements suggests that the resistance of hardened cement paste to natural carbonation is higher in PC than in blended cements after exposure to natural carbonation. Refinement of the porosity after carbonation was observed for all cements, which is due to the portlandite consumption and calcite formation which has

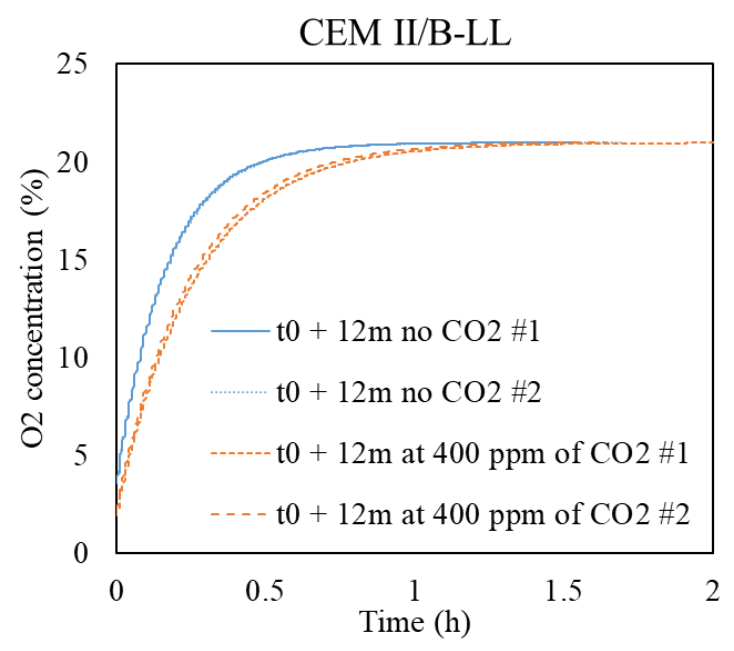

Figure 4. Oxygen diffusion curves for CEM II/B-LL exposed to natural carbonation for 12 month and $\mathrm{CO}_{2}$-free atmosphere at the same $\mathrm{RH}=70 \%$.

Table 3. Values of diffusion coefficients for systems presented in Figure 4 and total porosity obtained from MIP.

\begin{tabular}{lll}
\hline & $\mathrm{K}\left(\mathrm{m}^{2} / \mathrm{s}\right)$ & Porosity $(\%)$ \\
\hline $\mathrm{t}_{0}+12 \mathrm{~m} \mathrm{no} \mathrm{CO}_{2} \# 1$ & $4.92 \cdot 10^{-8}$ & 24.4 \\
$\mathrm{t}_{0}+12 \mathrm{~m} \mathrm{no} \mathrm{CO}_{2} \# 2$ & $4.81 \cdot 10^{-8}$ & \\
$\mathrm{t}_{0}+12 \mathrm{~m} \mathrm{400} \mathrm{ppm} \mathrm{C0} \mathrm{pl}_{2} \#$ & $2.97 \cdot 10^{-8}$ & 19.5 \\
$\mathrm{t}_{0}+12 \mathrm{~m} \mathrm{400} \mathrm{ppm} \mathrm{C0}{ }_{2} \# 2$ & $3.27 \cdot 10^{-8}$ & \\
\hline
\end{tabular}

a higher molar volume. There is no alteration in phase assemblage (including portlandite and calcite) in systems exposed to $\mathrm{CO}_{2}$-free atmosphere, however there is a change in pore distribution resulting in an increase of the capillary pores during exposure of the samples to lower RH (70 $\%)$. This has a practical relevance for correctly comparing carbonated samples with non-carbonated ones. Exposure of the samples in the same conditions as during carbonation, but without $\mathrm{CO}_{2}$, seems to be a correct way to obtain the relevant reference for carbonated samples. Results obtained form mercury intrusion porosimetry corresponds well with the gas diffusion measurement showing lower diffusion coefficient for carbonated sample (here limestone blend). Diffusion measurement is also going to be performed for the other cement systems.

Acknowledgements: This research has been supported by the SNF project (no. 154062) titled "Formulation, use and durability of concrete with low clinker cements".

\section{References}

[1] S. Matthews, Design of durable concrete structures (IHS BRE, 2014)

[2] T. Bellezze, G. Roventi, E. Barbaresi, N. Ruffini, R. Fratesi, Materials and corrosion 62, 155 (2011)

[3] A. Neville, Properties of concrete. fourth and final edition standards (1996) 
[4] L. Abosrra, A. Ashour, M. Youseffi, Construction and Building Materials 25, 3915 (2011)

[5] M. Auroy, S. Poyet, P. Le Bescop, J.M. Torrenti, T. Charpentier, M. Moskura, X. Bourbon, Cement and Concrete Research 74, 44 (2015)

[6] F. Georget, J.H. Prevost, B. Huet, CEMENT AND CONCRETE RESEARCH 104, 1 (2018)

[7] T.A.B.J. Kropp, H. Hilsdorf, Special Publication 114, 1413 (1989)

[8] R. Snellings, A practical guide to microstructural analysis of cementitious materials. CRC Press, Boca Raton pp. 107-176 (2016)

[9] B. Lothenbach, P. Durdzinski, K. De Weerdt, in A Practical Guide to Microstructural Analysis of Cementitious Materials (CRC Press Oxford, UK,
2016), pp. 177-212

[10] E. Berodier, J. Bizzozero, A.C. Muller, Mercury intrusion porosimetry (CRC Press: Boca Raton, 2016)

[11] M. Boumaaza, B. Huet, G. Pham, P. Turcry, A. AitMokhtar, C. Gehlen, Materials and Structures 51, 51 (2018)

[12] V. Ngala, C. Page, Cement and Concrete Research 27, 995 (1997)

[13] K. Sing, L. Parrott, A. Rahman, D. Pearson, Philosophical Transactions of the Royal Society of London Series A 310, 165 (1983)

[14] R. Patel, L. Parrott, J. Martin, D. Killoh, Cement and Concrete research 15, 343 (1985)

[15] R. Patel, D. Killoh, L. Parrott, W. Gutteridge, Materials and Structures 21, 192 (1988) 